\title{
Experimental Study on the Dynamics of A Bottom-hinged Oscillating Wave Surge Converter
}

\author{
Chuanchao $\mathrm{Xu}^{1,}$, , Xiangnan Wang ${ }^{2, \mathrm{~b}}$ and Zhenyuan Wang ${ }^{3, \mathrm{c}}$ \\ ${ }^{1}$ School of Civil Engineering, Tianjin University, China \\ ${ }^{2}$ National Ocean Technology Center, China \\ ${ }^{3}$ School of Mechanical Engineering, Tianjin University, China \\ ahmysxcc@163.com, bnotckj@vip.sina.com, cwzy769960293@163.com
}

\begin{abstract}
Keywords: wave energy; oscillating wave surge converter; experimental study; regular wave. Abstract. The bottom-hinged oscillating wave surge converter (OWSC) is a type of wave energy device that consists of a buoyant flap that is free to oscillate about a pivot. It completely penetrates the water column and is located within the near shore region. This paper presents an experimental study on the dynamics of the device in regular waves. In the experiments, dynamic properties involving natural period, pitching amplitude were analyzed, and rotary dampers were used to simulate the mechanical performance and characteristics of the power take-off system. Besides, two flap models with different thickness, five cases of sea states, both fully submerged and surface-piercing conditions were considered. It is found that the natural period of the flap increases as the draft increases initially and decreases afterwards. The pitching amplitude of the flap increases obviously when its natural period is close to that of the incident wave.
\end{abstract}

\section{Introduction}

Extracting wave energy from the ocean has drawn significant attentions in recent years, resulting in various inventions and developments of wave energy converters (WECs). The European Marine Energy Center (EMEC) categorizes WECs into several types as follows: Attenuator, Point Absorber, Oscillating Wave Surge Converter (OWSC), Oscillating Water Column (OWC), Overtopping, Terminator, Submerged Pressure Differential, Bulge Wave and Rotating Mass. The most popular, theoretical well-developed one among these WEC types is the Point Absorber, (Falnes and Budal, 1978; Evans, 1981; Mei, 1992) [1, 2]. The most famous OWSC is the Oyster developed by the company Aquamarine Power since the early 2000s, in close collaboration with Queen's University Belfast (Whittaker, 2007; Whittaker and Folley, 2011) [3, 4]. Oyster consists of a large buoyant flap, hinged near the seabed and oscillating back and forth under the action if the incident waves. The wave driven, oscillating motion of the flap is converted into electrical energy by pumping high pressure water ashore to drive a hydro-electric turbine (Whittaker, 2007) [5].

The bottom-hinged oscillating wave surge converter interacts directly with the near shore waves and extracts energy by rotating about the pivot in the bottom of the devices. Extensive research showed that this type of WEC had a high energy efficiency and, theoretically, a WEC oscillating in surge could absorb twice that of a body oscillating in heave [6]. Despite the simplicity of the design and the operation of the device itself, it is shown that established theories of WEC, such as point-absorber and terminator theory, are inadequate to fully describe the performance of such type of device. Accurately reproducing the behavior of WEC needs a physical model test.

This paper presents an experimental study on the dynamics of the bottom-hinged flap, which can be fully-submerged or surface piercing. The first section presents a brief description of the experimental procedure. In the second section, the result and discussion about the effects of thickness and draft are given.

\section{Experimental setup}

In this section, the experimental facilities that have been used to test the performance of the model design for the discussed WEC are presented in detail. In Tianjin University, the experiments 
were carried out in a wave tank, which was $137 \mathrm{~m}$ in length, $7 \mathrm{~m}$ in width and $3 \mathrm{~m}$ in depth. There is a push-plate-type wave maker at one end of the tank and a damping zone at the other end. There are 5 cases of wave states, shown in the Table 1.

Table 1. Wave states.

\begin{tabular}{|c|c|c|c|c|c|}
\hline \multirow{2}{*}{$\begin{array}{c}\text { Wave } \\
\text { Elements }\end{array}$} & \multicolumn{5}{|c|}{ Sea States } \\
\cline { 2 - 6 } & Case 1 & Case 2 & Case 3 & Case 4 & Case 5 \\
\hline Height $(m)$ & 0.125 & 0.125 & 0.125 & 0.188 & 0.25 \\
\hline Period $(s)$ & 1.75 & 2.5 & 3.0 & 2.0 & 2.0 \\
\hline
\end{tabular}

\section{The model and damping}

The flap was deployed in the middle of the wave tank, and the distance between the model and the wave maker is $45 \mathrm{~m}$. A frame is required to support the flap which is allowed to move up and down through the roller-rail system with the latter rigidly attached to the frame. In this experiment, rotary dampers are used to simulate the mechanical performance and characteristics of the power take-off system. The damping moment of the dampers applied on the device is $15 N M$. A computer-based drawing of the flap is shown in Fig. 1. The frame and the physical model are shown in Fig. 2. The detailed parameters of the flap are shown in Table 2.

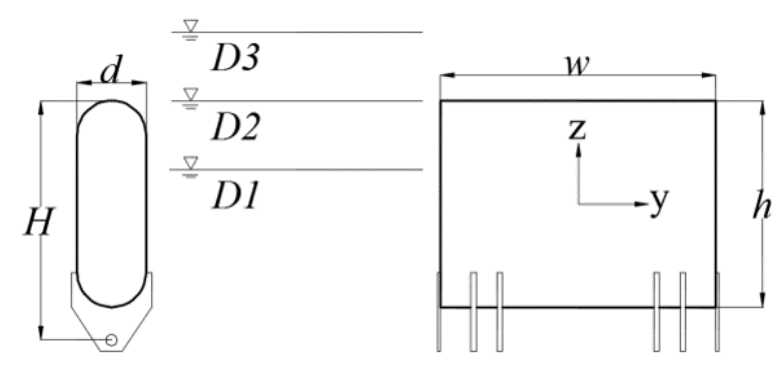

Fig. 1. Drawing of the flap.

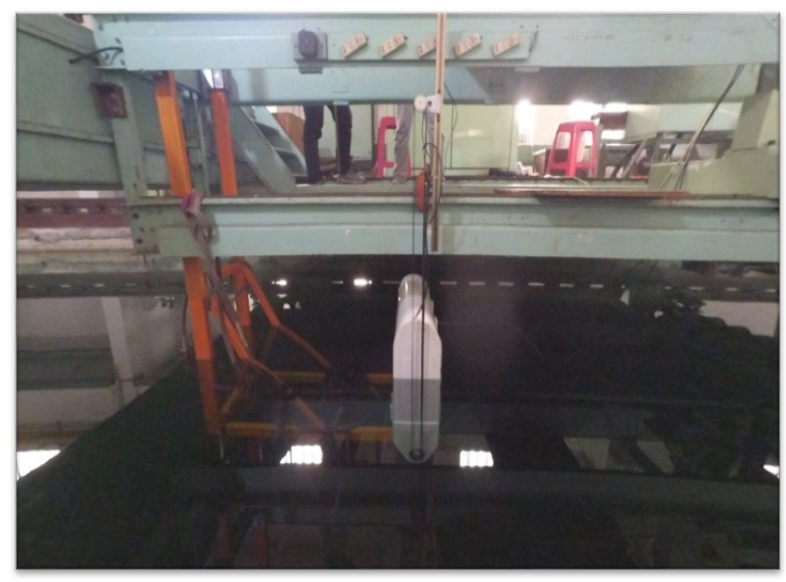

Fig. 2. Frame and the physical model.

Where $d$ is the thickness of the flap, $w$ is the width and $H$ is the length from pivot to the top of the flap. The flap was mounted on the frame which was fixed on the trailer. $D 1, D 2, D 3$ represents the position of flap with a draft of $50 \mathrm{~cm}, 75 \mathrm{~cm}, 100 \mathrm{~cm}$, respectively. 
Table 2. Detailed parameters of the flap.

\begin{tabular}{|c|c|c|}
\hline \multirow{2}{*}{ Parameters } & \multicolumn{2}{|c|}{ Flaps } \\
\cline { 2 - 3 } & Flap 1 & Flap 2 \\
\hline Thickness $(\mathrm{cm})$ & 25 & 20 \\
\hline Width $(\mathrm{cm})$ & 100 & 100 \\
\hline Height $(\mathrm{cm})$ & 75 & 75 \\
\hline Mass $(\mathrm{kg})$ & 42.2 & 33.8 \\
\hline Moment of Inertia $\left(\mathrm{kg} \cdot \mathrm{m}^{2}\right)$ & 2.7 & 2.3 \\
\hline
\end{tabular}

\section{Result and Discussion}

\section{Natural Period}

It will always be beneficial to tune a wave energy converter to the incident wave period [6]. The dynamics of bottom-hinged pitching flap type WECs tend to be inertia dominated and the natural pitching period can be approximately calculated using Equation 1.

$$
T_{N}=2 \pi \sqrt{I+k_{\mathrm{p}}} \text {. }
$$

Where $T_{N}$ is the natural period of the flap, $I$ is total moment of inertia and $k_{p}$ is the pitch stiffness. The pitch stiffness is a restoring moment due to the buoyancy of the flap. The inertia term consists of the moment of inertia of the mass of the flap and the added moment of inertia associated with the mass water attached to the flap surface. The natural period data gained from the free damping motion experiments is shown in the Fig.3, and Table 3.

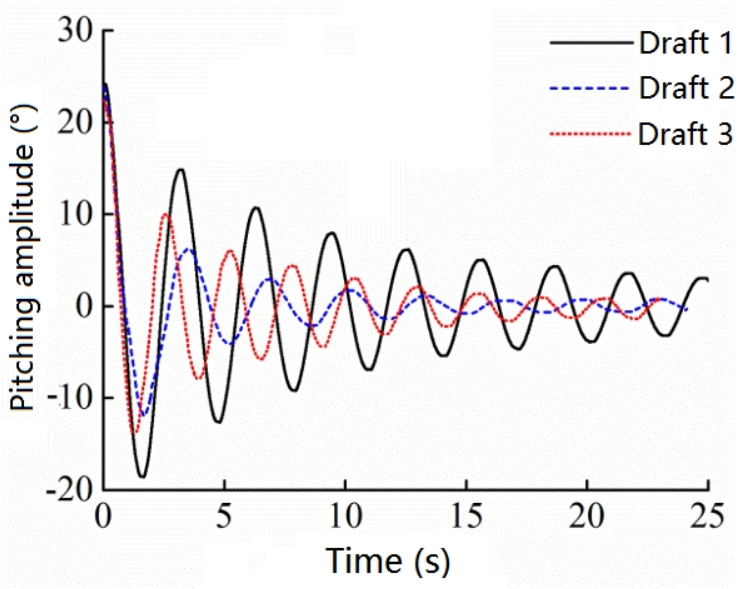

(a)

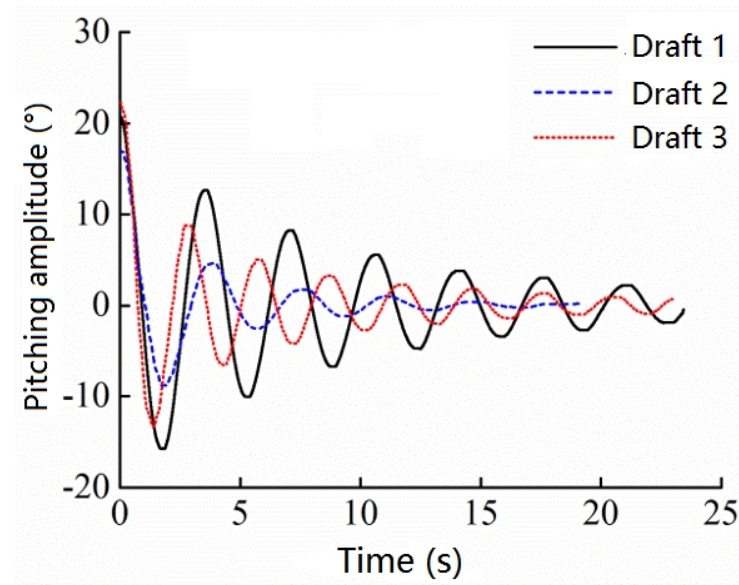

(b)

Fig. 3. Free damping motion: (a) this is the results of Flap 1, (b) this is the results of Flap 2 Where Draft 1, 2, 3 represents the draft of the flap is $50 \mathrm{~cm}, 75 \mathrm{~cm}, 100 \mathrm{~cm}$, respectively.

Table 3. Natural periods of the flaps $T_{N}$.

\begin{tabular}{|c|c|c|c|}
\hline \multirow{2}{*}{$\begin{array}{l}\text { Natural } \\
\text { Periods }\end{array}$} & \multicolumn{3}{|c|}{ Draft of the Flaps $(\mathrm{cm})$} \\
\cline { 2 - 4 } & 50 & 75 & 100 \\
\hline$T_{N 1}(s)$ & 3.15 & 3.45 & 2.55 \\
\hline$T_{N 2}(s)$ & 3.35 & 3.81 & 2.87 \\
\hline
\end{tabular}

Where $T_{N 1}, T_{N 2}$ is the natural period of Flap1, Flap 2, respectively. 


\section{Dynamic Response}

The dynamic responses of flaps in different cases are shown in Fig. 5. Responses in different drafts are shown in Fig. 6. And the effects of thickness, compared in same case of sea state and draft, are shown in Fig. 7.

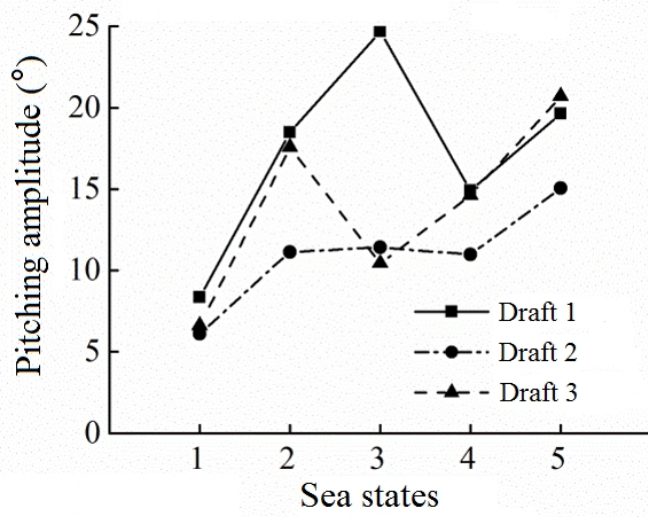

(a)

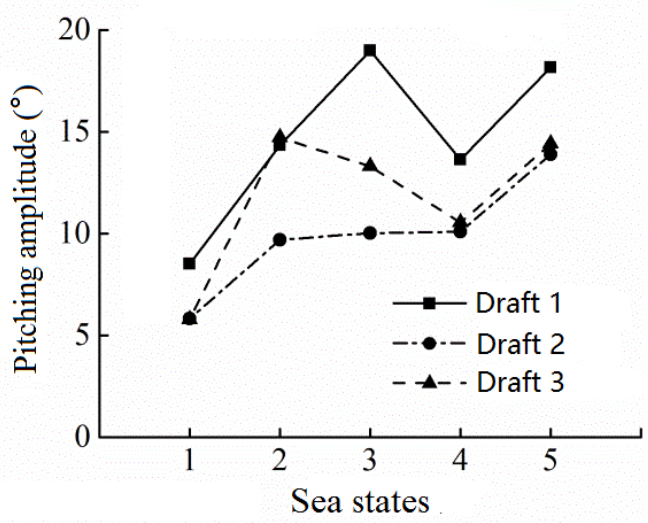

(b)

Fig. 4. Dynamic responses in different sea states: (a) is the result of Flap 1, (b) is the result of Flap 2.

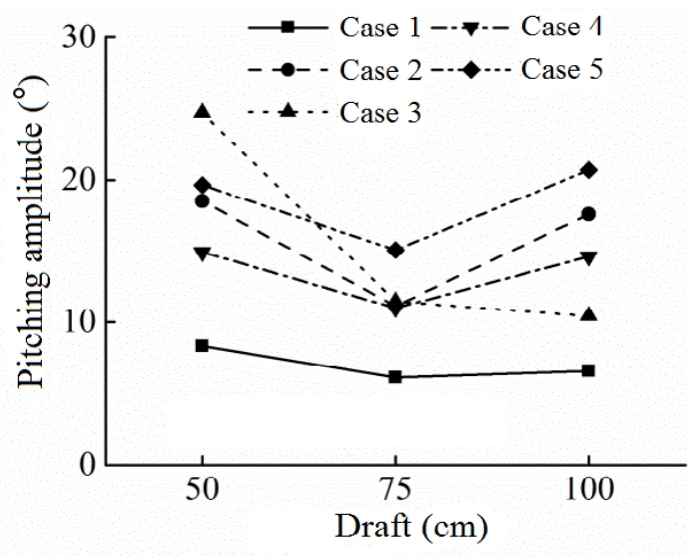

(a)

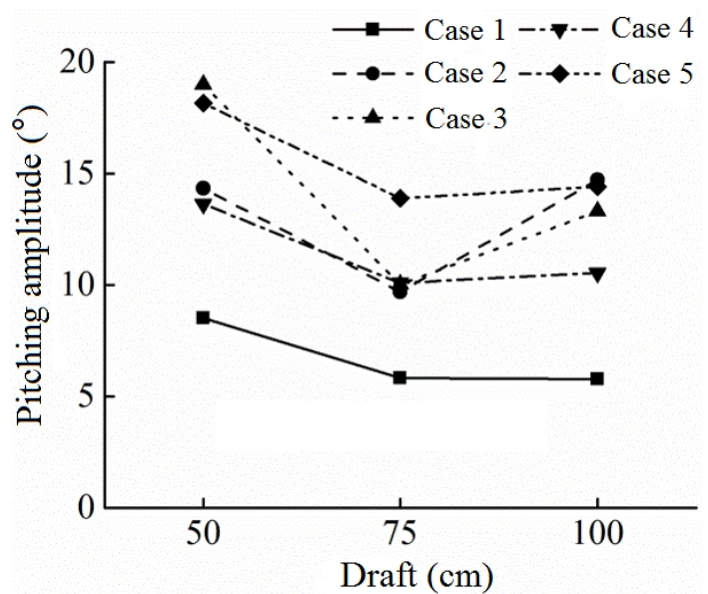

(b)

Fig. 5. Dynamic responses in different drafts: (a) is the result of Flap 1, (b) is the result of Flap 2.

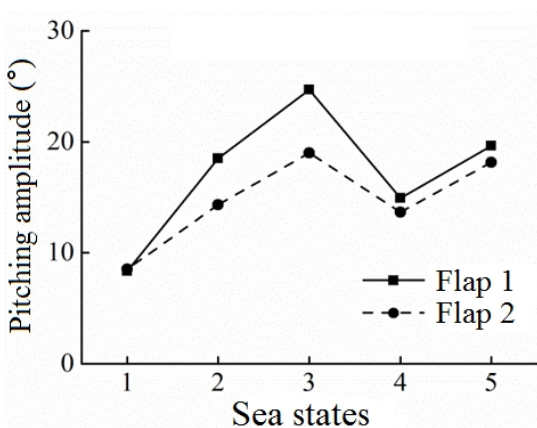

(a)

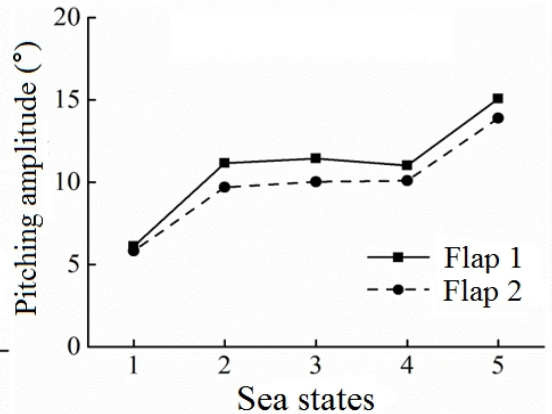

(b)

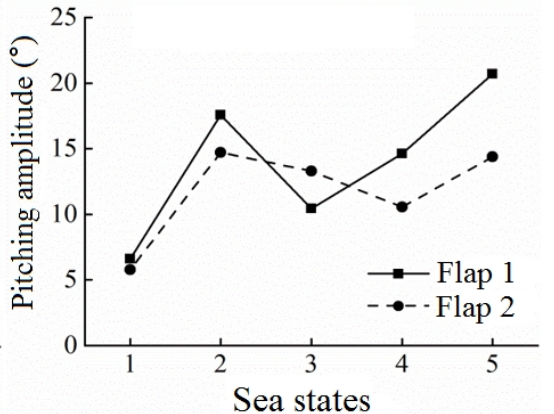

(c)

Fig. 6. Dynamic responses with different thickness: (a), (b), (c) is the result in Draft 1, Draft 2, Draft 3 , respectively.

\section{Conclusions}

In this paper, an experimental investigation of the dynamic response of OWSC in regular wave is presented. Two kinds of thickness, three different drafts and five cases of sea states were performed in the experiment. The interest is focused onto the pitching response which is closely connected to the total energy absorption. The following concluding remarks are obtained. 
1.The natural period of the flap increases as the draft increases initially and decreases afterwards, with the effect of both the static stiffness and the additional moment of inertia.

2.The amplitude of the flap motion increases obviously when its natural period is close to that of the incident wave. When the wave period deviates from the device's natural period, the motion amplitude will also increase remarkably with wave amplitude increasing.

3.The flap has obviously different performances without changing the width and height and changing its thickness only. In the sea state performed in this experiment, the performance of flap with the thickness of $25 \mathrm{~cm}$ is better than that of flap with the thickness of $20 \mathrm{~cm}$.

\section{Acknowledgements}

This work was financially supported by the Special Fund for Marine Renewable Energy of the Ministry of Finance of China (No. QDME2013ZB01).

\section{References}

[1] K. Budal, J. Falnes. Wave power conversion by point absorbers: A Norwegian project[J]. International Journal of Ambient Energy, 1982, 3(2):59-67.

[2] Chiang C M. The Applied Dynamics of Ocean Surface Waves[M]// The applied dynamics of ocean surface waves /. Wiley, 1983:321-321.

[3] Chang $\mathrm{Y} \mathrm{C}$, Chen $\mathrm{D} \mathrm{W}$, Chow $\mathrm{Y} \mathrm{C}$, et al. THEORETICAL ANALYSIS AND SPH SIMULATION FOR THE WAVE ENERGY CAPTURED BY A BOTTOM-HINGED OWSC[J]. Journal of Marine Science \& Technology, 2015, 23(6):901-908).

[4] Folley M, Whittaker T W T, Hoff J V. The design of small seabed-mounted bottom-hinged wave energy converters[J]. 2007.

[5] Doherty K J, Folley M, Doherty R, et al. Extreme Value Analysis of Wave Energy Converters[C]// International Conference on Ocean and Polar Engineering, Isope. 2011.

[6] Wei Y, Abadie T, Henry A, et al. Wave interaction with an Oscillating Wave Surge Converter. Part II: Slamming[J]. Ocean Engineering, 2016, 113:319-334.

[7] Henry A, Doherty K, Cameron L, et al. Advances in the Design of the Oyster Wave Energy Converter[C]// Marine Renewables and Offshore Wind Conference, Royal Institute of Naval Architects. 2010. 